\title{
Self-administered versus interview-based questionnaires among patients with intermittent claudication: Do they give different results? A cross-sectional study
}

\author{
Questionários autoadministrados versus administrados por entrevistador para \\ pacientes com claudicação intermitente: Os resultados são diferentes? \\ Um estudo transversal
}

Francisco Lozano', José María Lobos", José Ramón March"', Eduardo Carrasco" , Marcello Barbosa Barros`", José Ramón González-Porras" Spanish National Health Service, Salamanca, Spain

'MD, PhD. Angiology and Vascular Surgery Department, Hospital Universitario de Salamanca and Instituto de Investigación Biomédica de Salamanca (IBSAL), Salamanca, Spain.

"MD, PhD. Primary Care Physician, Centro de Salud Villablanca, Madrid, Spain.

"'MD. Angiology and Vascular Surgery Department, Hospital Universitario de Getafe, Madrid, Spain.

"MD. Primary Care Physician, Centro de Salud Jesús H. Gómez Tornero, Abarán, Murcia, Spain. ${ }^{\mathrm{V}} \mathrm{MD}, \mathrm{PhD}$. Angiology and Vascular Surgery Department, Hospital Universitario de Valladolid, Valladolid, Spain.

vMD, PhD. Hematology Department, Hospital Universitario de Salamanca and Instituto de Investigación Biomédica de Salamanca (IBSAL), Salamanca, Spain.

\section{KEY WORDS:}

Intermittent claudication.

Quality of life.

Questionnaires.

Validation studies.

Peripheral arterial disease.

\section{PALAVRAS-CHAVE:}

Claudicação intermitente.

Qualida de vida.

Questionários.

Estudos de validação

Doença arterial periférica.

\begin{abstract}
CONTEXT AND OBJECTIVE: Many clinical investigations use generic and/or specific questionnaires to obtain information about participants and patients. There is disagreement about whether the administration method can affect the results. The aim here was to determine whether, among patients with intermittent claudication $(I C)$, there are differences in the Walking Impairment Questionnaire (WIQ) and European Quality of Life-5 Dimension (EQ-5D) scores with regard to: 1) the questionnaire administration method (self-administration versus face-to-face interview); and 2) the type of interviewer (vascular surgeon, VS, versus general practitioner, GP).

DESIGN AND SETTING: Cross-sectional observational multicenter epidemiological study carried out within the Spanish National Health Service.

METHODS: 1,641 evaluable patients with IC firstly completed the WIQ and EQ-5D questionnaires and then were interviewed by their doctor on the same day. Pearson correlations and Chi-square tests were used. RESULTS: There was a strong correlation $(r>0.800 ; P<0.001)$ between the two methods of administering the WIQ and EQ-5D questionnaires, and between the VS and GP groups. Likewise, there was a high level of concordance $(P>0.05$ ) between the different dimensions of the WIQ-distance and EQ-5D (selfadministration versus face-to-face) in the VS and GP groups.

CONCLUSION: There was no difference between the different methods of administering the WIQ and EQ-5D questionnaires, among the patients with IC. Similarly, the two types of interviewers (VS or GP) were equally valid. Therefore, it seems unnecessary to expend effort to administer these questionnaires by interview, in studies on IC.
\end{abstract}

\section{RESUMO}

CONTEXTO E OBJETIVO: Muitas investigações clínicas usam questionários genéricos e/ou específicos para obter informações sobre os participantes e pacientes. Não se sabe se o modo de administração pode afetar os resultados. O objetivo foi determinar se, nos pacientes com claudicação intermitente (Cl), existem diferenças nas pontuações do Walking Impairment Questionnaire (WIQ) e do European Quality of Life-5 Dimension (EQ-5D) no que diz respeito a: 1) a forma de administrar o questionário (autoadministrado versus entrevista presencial); e 2) o tipo de entrevistador: cirurgião vascular (CV) ou médico generalista (MG).

TIPO DE ESTUDIO E LOCAL: Estudo epidemiológico observacional, transversal, multicêntrico realizado no Serviço Nacional de Saúde espanhol.

METODO: 1.641 pacientes avaliáveis com Cl completaram inicialmente o WIQ e questionários EQ-5, e depois, no mesmo dia, foram entrevistados pelo seu médico. Foram utilizados correlações de Pearson e testes de qui-quadrado.

RESULTADOS: Houve forte correlação $(r>0,800 ; P<0,001)$ entre os dois métodos de administração do WIQ e EQ-5D; e entre os grupos CV e MG. Também houve alto nível de concordância $(P>0,05)$ entre as diferentes dimensões do WIQ-distância e EQ-5D (autoadministrado versus entrevista presencial), nos grupos CV e MG.

CONCLUSÃO: Em pacientes com Cl, não há diferenças entre as diferentes formas de administrar os questionários WIQ e EQ-5D. Da mesma forma, os dois tipos de entrevistador (CV ou MG) foram igualmente válidos. Portanto, não parece necessário despender esforço para administrar esses questionários através de entrevista, em estudos de $\mathrm{Cl}$. 


\section{INTRODUCTION}

Many epidemiological and clinical studies, including clinical trials, use information directly reported by study participants. There are many generic and disease-specific questionnaires reported in the medical literature that are used by researchers to obtain relevant information about their patients. Research into peripheral arterial disease (PAD) and, specifically, intermittent claudication (IC) also uses generic or specific questionnaires to measure outcomes such as deterioration in walking or health-related quality of life (HRQOL). The former include the Walking Impairment Questionnaire (WIQ), while in the European context, the European Quality of Life-5 Dimensions (EQ-5D) is recommended for evaluating HRQOL among patients with IC. ${ }^{1,2}$

Most of these questionnaires have been validated from the original version to other languages; for example, the WIQ has been validated in Portuguese and Spanish. ${ }^{3-5}$ The WIQ and EQ-5D were originally designed to be self-administered and have been used in that way in most studies on IC. ${ }^{6,7}$ However, these questionnaires may be completed by other means; for example, with the aid of an interviewer (face-to-face or by telephone). While the latter methods have the advantage of directly controlling the process and thereby offer the possibility of obtaining superiorquality results, self-administration methods (in the consultation room or at home, and returned by post or e-mail) do not require research staff, enable lower research costs and allow patients greater freedom to express their responses to the questions. However, only Conley et al. have evaluated the effects of the two methods of administering the WIQ. ${ }^{8}$ Thus, while some studies (not on IC) have shown differences between administration formats, ${ }^{9-12}$ others have found no statistically significant differences. ${ }^{13-17}$ For these reasons, in some epidemiological studies, self-administered and interviewer-led questionnaires are available to accommodate the preferences, physical impediments or literacy of the participants.

\section{OBJECTIVE}

Our study aimed to examine whether, in a large cohort of patients with IC who had completed the WIQ and EQ-5D questionnaires, there were systematic differences in the scores that could be attributed to: 1) the administration method of the questionnaire (self-administration versus interview-based); and 2) the type of interviewer (vascular surgeon versus general practitioner).

\section{METHODS}

A cross-sectional observational multicenter epidemiological study on IC in Spain was carried out between May and December 2011, using previously published data. ${ }^{18}$

Vascular surgeons (VSs) and general practitioners (GPs) were identified through the scientific societies participating in the study. All the physicians had previously taken part in epidemiological studies about some type of vascular pathology. Patients were recruited during visits to hospitals (in the case of the VSs) or health centers (in the case of the GPs) within the National Health Service. Each researcher was obliged to include 3-4 consecutive patients affected by IC. The diagnosis of IC was made through the clinical history (including a positive Edinburgh questionnaire result), physical examination and ankle-brachial index (ABI $<0.90$ or $>1.3$, in diabetic patients), following previously described methods. ${ }^{19,20}$ The ABI of each extremity was calculated by dividing the highest pressure obtained in either of the leg arteries by the maximum brachial value. In the records of each patient, only the claudicant limb, or the lower ABI in the bilateral cases, was taken into account. ${ }^{21}$

Each physician compiled the information on a data collection sheet covering the demographic and clinical characteristics of the patient. Two questionnaires were completed on the same occasion: WIQ and EQ-5D.

The WIQ is a questionnaire specific to IC that evaluates four parameters: pain, distance covered, speed and stair-climbing ability. ${ }^{6}$ For each domain, a score for the ranked difficulty of doing each of the items is calculated, ranging from 0 (total incapacity) to 100 (full capacity). The Spanish version of the questionnaire was used. ${ }^{5}$

The EQ-5D questionnaire is an instrument designed by a European group for measuring HRQOL. ${ }^{7}$ It is a generic questionnaire that is widely used in research because of its ease of use. It has three components. The first evaluates five factors: mobility, self-care, everyday activities, pain/discomfort and anxiety/ depression. The scores obtained are summarized as an overall index from 0 (worst state of health) to 1 (best state of health). The second part consists of a visual analogue scale (VAS), in the form of a thermometer, with end points of "worst" and "best" imaginable state of health (scored from 0 to 100, respectively). The third part (patient preference values) was not evaluated. The Spanish version, which has also been validated for use in primary care, was used. ${ }^{22,23}$

Both questionnaires were administered through two methods: self-administration (before the start of the aforementioned consultation), and a subsequent face-to-face interview by the physician (VS or GP). We applied the questionnaire in these two forms without any relevant time interval between them. Initially, the patients completed the WIQ and EQ-5D, in that order, without any help. Once that phase was completed, they filled in the questionnaires in the same order with the help of the doctor. We can consider the latter phase to be the 'ideal means of applying the questionnaires' or to be a control for the former phase. The formats of the self-administered and interview-based questionnaires were identical. 


\section{Statistical analysis}

A data file was created in PASW (version 18; IBM, New York, NY, USA). Continuous variables were summarized as means and standard deviations; categorical variables were expressed as percentages. Normally and non-normally distributed continuous variables were compared using Student's t test and the Mann-Whitney $U$ test, respectively. Categorical variables were examined using the $\chi^{2}$ or Fisher's exact test; the latter was used when the expected frequencies of one or more categories was less than 5. The Pearson correlation coefficient ( $r$ ) of each dimension of the WIQ and EQ-5D was calculated for each of the two methods of questionnaire administration. Values of $\mathrm{r}$ were interpreted as follows: $0.0-0.19$, very weak correlation; 0.20-0.39, weak; $0.40-0.59$, moderate; $0.60-0.79$, strong; and 0.80-1.0, very strong. ${ }^{24}$ All comparisons were based on a $95 \%$ confidence interval. Results were taken to be statistical significant when $\mathrm{P}<0.05$.

\section{Ethics approval for the study}

The study was approved by the Scientific and Ethics Committees of the Hospital Clinic (Barcelona, Spain) on March 10, 2011 (Protocol: SEA-NUL_2011_01).

\section{RESULTS}

Six hundred and twenty-five researchers provided information from 2,127 consecutive patients affected with IC, of whom 486 patients $(22.8 \%)$ were removed from the study because their data were incomplete. Thus, 1,641 patients were evaluated: 920 patients from 249 VSs and 721 from 247 GPs. The reasons for exclusion and removal are shown in Table 1. Patients and

Table 1. Patients with intermittent claudication (IC) and criteria for inclusion, exclusion and withdrawal*

\begin{tabular}{lccc} 
Criterion & $\begin{array}{c}\text { Number of } \\
\text { patients }\end{array}$ & VS group & GP group \\
\hline Patient with IC & 2,257 & 1,261 & 996 \\
Exclusion & $130(5.8)$ & $69(5.5)$ & $61(6.1)$ \\
\hline Inclusion & $2,127(94.2)$ & $1,192(94.5)$ & $935(93.9)$ \\
\hline Removed & $486(22.8)$ & $272(22.8)$ & $214(22.9)$ \\
\hline Evaluated & $1,641(77.2)$ & $920(77.2)$ & $721(77.1)$ \\
Cause of removal & & & \\
$\quad$ Incomplete data & $23(4.7)$ & $11(4.0)$ & $12(5.6)$ \\
$\quad$ Uncompleted & $463(95.3)$ & $261(96.0)$ & $202(94.4)$ \\
$\quad$ questionnaires & & & \\
Reasons & & & \\
$\quad$ EQ-5D self & $85(18.4)$ & $46(17.6)$ & $39(19.3)$ \\
EQ-5D interview & $25(5.4)$ & $15(5.7)$ & $10(4.9)$ \\
WIQ self & $210(45.4)$ & $118(45.2)$ & $92(45.5)$ \\
$\quad$ WIQ interview & $35(7.6)$ & $22(8.4)$ & $13(6.4)$ \\
EQ-5D + WIQ (all) & $108(23.3)$ & $60(23.0)$ & $48(23.8)$ \\
\hline
\end{tabular}

*Number (percentage).

EQ-5D = European Quality of Life-5 Dimension; WIQ = Walking Impairment Questionnaire. researchers were selected from across the entire country, including urban and rural areas.

The demographic and clinical characteristics of the groups are summarized in Table 2. Patients in the VS group had lower $\mathrm{ABI}$ than those in the GP group ( 0.63 versus 0.71 ; $\mathrm{P}<0.001)$.

The scores for the various components of the WIQ, selfadministered and administered through an interview with a VS or GP, are shown in Table 3. The group of patients interviewed by the VSs had significantly worse scores for the dimensions of pain (47.1\% versus $50.4 \% ; \mathrm{P}<0.001)$ and distance covered $(34.1 \%$ versus $36.4 \% ; \mathrm{P}=0.007)$.

Table 2. Baseline characteristics of patients with intermittent claudication

\begin{tabular}{|c|c|c|}
\hline & VS group & GP group \\
\hline Number of patients & 920 & 721 \\
\hline Male $^{*}$ & 717 (77.9) & $518(71.8)$ \\
\hline Age (years), mean \pm SD & $68.2 \pm 9.8$ & $68.6 \pm 8.9$ \\
\hline Body mass index, mean $\pm S D$ & $27.6 \pm 3.6$ & $28.2 \pm 3.7$ \\
\hline \multicolumn{3}{|l|}{ Cohabitation* } \\
\hline Alone & $197(21.4)$ & $150(20.8)$ \\
\hline Couple/family & $666(72.4)$ & $522(72.4)$ \\
\hline Others & $47(5.1)$ & $40(5.5)$ \\
\hline Not known/answered & $10(1.1)$ & $9(1.2)$ \\
\hline \multicolumn{3}{|c|}{ Place of residence (numbers of inhabitants)* } \\
\hline$<50,000$ & $297(32.3)$ & $312(43.3)$ \\
\hline $50,000-200,000$ & $279(30.3)$ & $248(34.4)$ \\
\hline $200,000-500,000$ & $191(20.8)$ & 99 (13.7) \\
\hline $500,000-1,000,000$ & $52(5.6)$ & $33(4.6)$ \\
\hline$>1,000,000$ & $97(10.5)$ & $26(3.6)$ \\
\hline Not known/answered & $4(0.4)$ & $3(0.4)$ \\
\hline \multicolumn{3}{|l|}{ Employment situation* } \\
\hline Active working & $176(19.1)$ & $153(21.2)$ \\
\hline Unemployed/off work & $131(14.2)$ & $78(10.8)$ \\
\hline Retired & $613(66.6)$ & $487(67.5)$ \\
\hline Not known/answered & $1(0.1)$ & $3(0.4)$ \\
\hline \multicolumn{3}{|c|}{ Family history of cardiovascular disease* } \\
\hline Yes & $541(58,8)$ & $380(52,7)$ \\
\hline No & $351(38.1)$ & $272(37.7)$ \\
\hline Not known/answered & $28(3.1)$ & $69(9.6)$ \\
\hline \multicolumn{3}{|l|}{ Cardiovascular risk factor ${ }^{*, \dagger}$} \\
\hline None & $23(2.5)$ & $29(4.0)$ \\
\hline Only one & 159 (17.3) & $129(17.9)$ \\
\hline Two & $343(37.3)$ & $266(36.9)$ \\
\hline Three & $302(32.8)$ & $236(32.7)$ \\
\hline All (four) & $93(10.1)$ & $61(8.5)$ \\
\hline \multicolumn{3}{|l|}{ Associated cardiovascular pathology* } \\
\hline Cardiac insufficiency & $86(9.3)$ & $61(8.5)$ \\
\hline Ischemic cardiopathy (angina) & $278(30.2)$ & $118(16.4)$ \\
\hline Arrhythmias & $85(9.2)$ & $55(7.6)$ \\
\hline Valvular heart diseases & $33(3.6)$ & $29(4.0)$ \\
\hline Stroke & $23(2.5)$ & $19(2.6)$ \\
\hline Renal insufficiency & $77(8.4)$ & $33(4.6)$ \\
\hline Ankle-brachial index, mean \pm SD & $0.63 \pm 0.19$ & $0.71 \pm 0.19$ \\
\hline
\end{tabular}

*Number (percentage) or mean \pm standard deviation (SD).

VS = vascular surgeon; GP = general practitioner; ${ }^{\dagger}$ (tobacco, diabetes mellitus, arterial hypertension and dyslipidemia). 
The WIQ scores obtained from both types of interviewer were somewhat higher on average than those obtained through self-reporting. However, only the higher score in the VS group (mean score 2.04 points higher) was statistically significant $(\mathrm{P}<0.05)$.

The correlations between self-administration and interviewbased methods of completing the questionnaire were very strong $(r=0.820-0.905)$, even when considering the two types of interviewer separately (Table 3 ).

The overall scores from the EQ-5D questionnaire were almost identical $(0.58 \pm 0.21)$ when administered through self-reporting and through interview with a VS, and likewise when the interviewer was a GP $(0.57 \pm 0.21)$. There were no differences between the VS and GP groups $(P=0.429)$. The correlation between the two methods of administering the questionnaire was very strong, whether the interviewer was a VS $(\mathrm{r}=0.850$; $\mathrm{P}<0.001)$ or a GP $(\mathrm{r}=0.828 ; \mathrm{P}<0.001)$.

Tables 4 and 5 compare the results from the various dimensions of the WIQ and EQ-5D obtained through self-administration and through interviews conducted by a VS or GP. No differences were found between these methods $(P>0.05)$.

\section{DISCUSSION}

Our results demonstrate that self-administration and interview by a physician are both valid approaches for evaluating patients with IC using the WIQ and EQ-5D questionnaires. Likewise, the correlation between the two modes of administering the questionnaires was high for both types of interviewer (VS and GP).

Table 3. Walking Impairment Questionnaire (WIQ) and EuroQol (EQ-5D). Survey mode

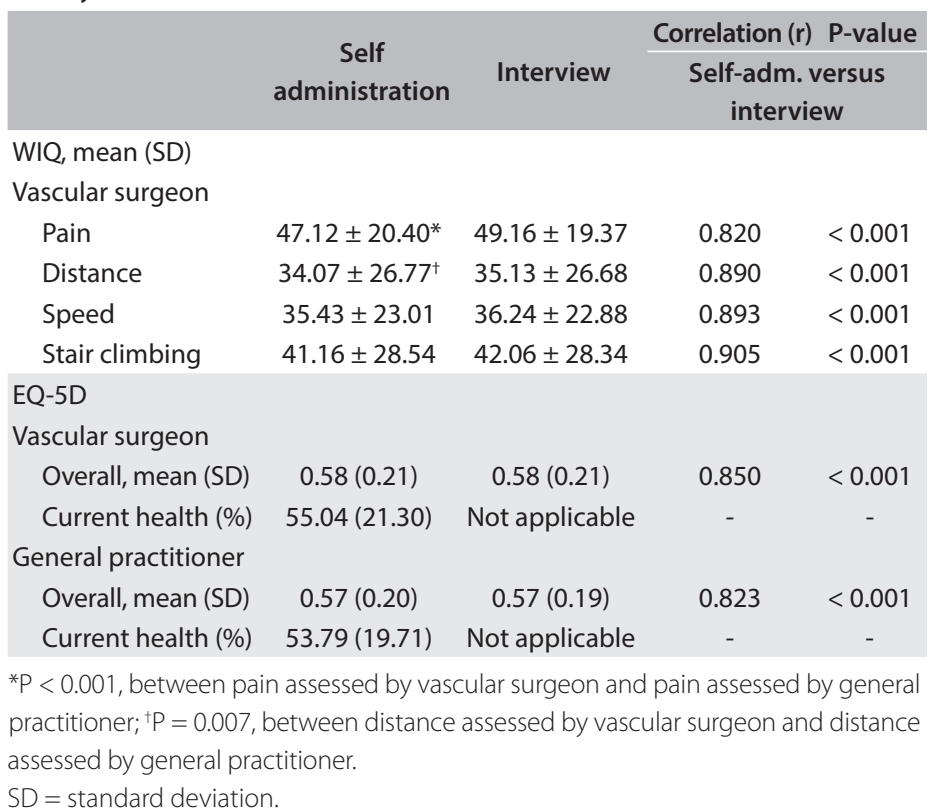

These findings are highly important, since if the different ways of administering a particular questionnaire were to produce different results in an epidemiological study or clinical trial, the estimates of the associations or the effects of the treatment investigated could be affected, thus raising the possibility of incorrect conclusions being drawn.

Table 4. Walking Impairment Questionnaire: distance dimensions (\%) through self-administration or interview, by vascular surgeons and general practitioners

\begin{tabular}{|c|c|c|c|c|c|c|}
\hline & \multicolumn{3}{|c|}{ Vascular surgeons } & \multicolumn{3}{|c|}{ General practitioners } \\
\hline & Self & Interview & $P$ & Self & Interview & $P$ \\
\hline \multicolumn{7}{|c|}{ 1. Walking indoors } \\
\hline Very high & 0.7 & 0.4 & & 0.4 & 0.2 & \\
\hline High & 2.9 & 2.4 & & 2.1 & 1.8 & \\
\hline Medium & 8.9 & 8.4 & 0.75 & 8.6 & 8.2 & 0.80 \\
\hline Low & 21.0 & 19.7 & & 32.0 & 30.9 & \\
\hline Any & 66.5 & 69.1 & & 56.9 & 58.9 & \\
\hline \multicolumn{7}{|l|}{ 2. Walk $15 \mathrm{~m}$} \\
\hline Very high & 1.7 & 1.5 & & 1.5 & 1.1 & \\
\hline High & 3.7 & 3.3 & & 2.6 & 2.4 & \\
\hline Medium & 11.2 & 10.4 & 0.66 & 12.3 & 12.3 & 0.96 \\
\hline Low & 24.3 & 22.1 & & 33.3 & 33.6 & \\
\hline Any & 59.1 & 62.7 & & 50.3 & 50.6 & \\
\hline \multicolumn{7}{|c|}{ 3. Walk $50 \mathrm{~m}$ (half square) } \\
\hline Very high & 4.3 & 3.6 & & 3.5 & 3.2 & \\
\hline High & 9.2 & 8.8 & & 6.7 & 6.4 & \\
\hline Medium & 20.9 & 19.9 & 0.80 & 24.8 & 24.3 & 0.97 \\
\hline Low & 24.9 & 24.7 & & 33.5 & 33.1 & \\
\hline Any & 40.7 & 43.0 & & 31.5 & 33.0 & \\
\hline \multicolumn{7}{|c|}{ 4. Walk 100 m (1 square) } \\
\hline Very high & 9.1 & 8.2 & & 5.8 & 5.5 & \\
\hline High & 18.9 & 18.0 & & 16.8 & 16.0 & \\
\hline Medium & 27.4 & 25.3 & 0.59 & 31.9 & 31.9 & 0.98 \\
\hline Low & 21.8 & 23.7 & & 29.3 & 29.4 & \\
\hline Any & 22.8 & 24.8 & & 16.2 & 17.2 & \\
\hline \multicolumn{7}{|c|}{ 5. Walk 200 m (2 squares) } \\
\hline Very high & 19.3 & 18.4 & & 12.6 & 12.1 & \\
\hline High & 27.0 & 25.5 & & 26.2 & 26.6 & \\
\hline Medium & 25.5 & 25.9 & 0.84 & 34.1 & 34.0 & 0.98 \\
\hline Low & 15.7 & 17.3 & & 19.1 & 19.8 & \\
\hline Any & 12.5 & 12.9 & & 8.0 & 7.5 & \\
\hline \multicolumn{7}{|c|}{ 6. Walk 300 m (3 squares) } \\
\hline Very high & 34.5 & 32.3 & & 25.1 & 23.7 & \\
\hline High & 29.7 & 29.8 & & 32.0 & 33.7 & \\
\hline Medium & 18.2 & 19.8 & 0.73 & 26.6 & 26.7 & 0.96 \\
\hline Low & 10.5 & 11.6 & & 12.9 & 12.6 & \\
\hline Any & 7.1 & 6.5 & & 3.4 & 3.3 & \\
\hline \multicolumn{7}{|c|}{ 7. Walk 500 m (5 squares) } \\
\hline Very high & 51.7 & 50.5 & & 40.8 & 40.5 & \\
\hline High & 24.2 & 24.7 & & 31.9 & 33.7 & \\
\hline Medium & 14.1 & 14.2 & 0.90 & 19.4 & 18.3 & 0.90 \\
\hline Low & 8.0 & 9.0 & & 6.2 & 6.3 & \\
\hline Any & 2.0 & 1.6 & & 1.7 & 1.2 & \\
\hline
\end{tabular}

Self $=$ self-administration . 
It is possible to measure an individual's capacity to walk. The treadmill widely used by VSs enables objective measurement of the walk of patients with IC and evaluation of the changes following an intervention program. Introduction of the WIQ has helped GPs measure the walking capacity of their patients without the need for sophisticated equipment. The WIQ has become a widely used instrument for evaluating the walking capacity of patients with claudication, ${ }^{25}$ and its scores correlate well with more objective measurements. ${ }^{26,27}$ The WIQ has been used jointly with various HRQOL questionnaires, thereby providing excellent overall information about the limitations of these patients.

IC patients have significantly poorer HRQOL than healthy controls, especially with regard to the physical domains. Of the various questionnaires that measure HRQOL, the EQ-5D has the great advantages of being simple to use (only five dimensions) and of being validated for IC, despite its generic nature. ${ }^{28,29}$

As Puhan et al. noted, ${ }^{15}$ most questionnaires of this type tend to be self-completed. Indeed, the WIQ and EQ-5D were originally designed to be self-administered, although they may also be completed through personal interview, over the telephone or by post. The aforementioned advantages and disadvantages make it necessary to compare these methods.

With regard to the WIQ, we are aware of only one study, by Coyne et al., ${ }^{8}$ that has compared the different administration methods. Although their study included a relatively small sample of 60 patients, it sought to validate the questionnaire for self-administration and telephone interviews, and found no significant differences in the scores on the four subscales of the WIQ (pain severity, distance, speed and stair-climbing), compared with control interviews. Our study also found no differences in the results obtained through the various forms of administration. In this type of study, in which a degree of psychological influence may be expected, a correlation coefficient of 0.70 or more can be considered to be very strong. ${ }^{30}$

Nevertheless, there were two notable observations:

1. As in other studies, albeit on other pathological conditions, ${ }^{31}$ we noted numerically higher scores when the questionnaires were administered by an interviewer, although the difference was only significant for the pain domain of the WIQ. This is commonly explained as being the result of social desirability bias, ${ }^{32}$ in which participants may state that they are less affected when interviewed by research staff than when the questionnaires are self-administered.

2. As in the study by Mahe et al., ${ }^{33}$ there was also a substantial number of errors and missing responses in the self-administered WIQ questionnaires. These patients were excluded from the study. In order to avoid any bias that may arise as a consequence, completion of the questionnaire would have to be supervised. In our study, the excluded and included patients did not differ with regard to items that might influence the socioeconomic characteristics of the two groups: age, sex, cohabitation, place of residence and type of job.

Table 5. EuroQol (EQ-5D) dimensions (\%) through self-administration or interview, between vascular surgeons and general practitioners

\begin{tabular}{|c|c|c|c|c|c|c|}
\hline & \multicolumn{3}{|c|}{ Vascular surgeons } & \multicolumn{3}{|c|}{ General practitioners } \\
\hline & Self & Interview & $\mathbf{P}$ & Self & Interview & $\mathbf{P}$ \\
\hline \multicolumn{7}{|l|}{ 1. Mobility } \\
\hline I have no problems in walking about & 11.5 & 12.0 & & 13.2 & 11.5 & \\
\hline I have some problems in walking about & 85.9 & 85.3 & 0.94 & 85.3 & 87.4 & 0.48 \\
\hline I am confined to bed & 2.6 & 2.7 & & 1.5 & 1.1 & \\
\hline \multicolumn{7}{|l|}{ 2. Self-care } \\
\hline I am unable to wash or dress myself & 2.2 & 1.8 & & 1.8 & 1.4 & \\
\hline \multicolumn{7}{|l|}{ 3. Everyday activities } \\
\hline I have no problems with performing my usual activities & 39.3 & 40.4 & & 37.6 & 37.4 & \\
\hline I have some problems with performing my usual activities & 53.7 & 53.6 & 0.61 & 57.1 & 58.2 & 0.74 \\
\hline I am unable to perform my usual activities & 7.0 & 6.0 & & 5.3 & 4.4 & \\
\hline I have extreme pain or discomfort & 15.7 & 12.8 & & 13.9 & 11.5 & \\
\hline \multicolumn{7}{|l|}{ 5. Anxiety/depression } \\
\hline I am not anxious or depressed & 58.3 & 55.8 & & 51.0 & 49.5 & \\
\hline I am moderately anxious or depressed & 32.8 & 36.3 & 0.22 & 41.5 & 43.6 & 0.70 \\
\hline I am extremely anxious or depressed & 8.9 & 7.9 & & 7.5 & 6.9 & \\
\hline
\end{tabular}

Self $=$ self-administration 
Although the EQ-5D has been widely used in cardiovascular studies, ${ }^{34,35}$ there are no published studies comparing the different formats for administering this questionnaire to patients with this type of pathological condition. The best match for the EQ-5D has been found among HIV patients, whose scores were very similar for the different administration methods (self-reporting versus interview) and types of interview (face-to-face versus telephone). ${ }^{13}$

Our study has some limitations. Apart from the considerable number of excluded patients, the study was also limited because it was not possible to carry out treadmill tests to measure the IC objectively. The use of ergometers is time-consuming and costly and requires control by specialist professionals. However, this omission may not be too important, since clinical manifestations and the WIQ can be used as an alternative to treadmill testing for objectively assessing functional walking ability. Forty percent of the patients recruited came from non-hospital consultations, thus justifying the use of the WIQ.

Another limitation of our study was the absence of a washout period between the two forms of administration of the questionnaires. In our study, this was sequential: first, self-administration (trial form); second, face-to-face (ideal application or control). Our aim was not to evaluate either of the questionnaires but to measure the equivalence between the two forms of administration. Evidently, when patients arrived at the interview they already had previous (and recent) experience, but this was minimized due to the doctor's influence on filling out the questionnaires. On the other hand, the doctor would have a decisive influence, were the sequence to be interview first, followed by self-administration.

\section{CONCLUSION}

Our study, which was carried out on a large sample of patients with intermittent claudication, provides evidence that the format of administration of the WIQ and EQ-5D questionnaires has no significant effect on the measurements, provided that the patient is able to fill out a self-applicable form. Consequently, it is not necessary to take into consideration the different formats of administration in this type of study, in analyzing the results within this scenario. This is fortuitous in that it avoids having to do unnecessary work. However, researchers should carefully consider the format of administration used, in order to avoid bias arising from the application method of the questionnaire chosen.

\section{REFERENCES}

1. Chetter IC, Spark JI, Dolan P, Scott DJ, Kester RC. Quality of life analysis in patients with lower limb ischaemia: suggestions for European standardisation. Eur J Vasc Endovasc Surg. 1997;13(6):597-604.

2. Mehta T, Venkata Subramaniam A, Chetter I, McCollum P. Assessing the validity and responsiveness of disease-specific quality of life instruments in intermittent claudication. Eur J Vasc Endovasc Surg. 2006;31(1):46-52.

3. Ritti-Dias RM, Gobbo LA, Cucato GG, et al. Translation and validation of the walking impairment questionnaire in Brazilian subjects with intermittent claudication. Arq Bras Cardiol. 2009;92(2):136-49.

4. Collins TC, Suarez-Almazor M, Petersen NJ, O'Malley KJ. A Spanish translation of the Walking Impairment Questionnaire was validated for patients with peripheral arterial disease. J Clin Epidemiol. 2004;57(12):1305-15.

5. Lozano FS, March JR, González-Porras JR, et al. Validation of the Walking Impairment Questionnaire for Spanish patients. Vasa. 2013;42(5):350-6.

6. Regensteiner JG, Steiner JF, Panzer RJ, Hiatt WR. Evaluation of walking impairment by questionnaire in patients with peripheral arterial disease. J Vasc Med Biol. 1990;2:142-52.

7. EuroQol Group. EuroQol--a new facility for the measurement of health-related quality of life. Health Policy. 1990;16(3):199-208.

8. Coyne KS, Margolis MK, Gilchrist KA, et al. Evaluating effects of method of administration on Walking Impairment Questionnaire. J Vasc Surg. 2003;38(2):296-304.

9. CookDJ, Guyatt GH, Juniper E, et al. Interviewer versus self-administered questionnaires in developing a disease-specific, health-related quality of life instrument for asthma. J Clin Epidemiol. 1993;46(6):529-34.

10. Kaminska M, Jobin V, Mayer $P$, et al. The Epworth Sleepiness Scale: self-administration versus administration by the physician, and validation of a French version. Can Respir J. 2010;17(2):e27-34.

11. Desai R, Durham J, Wassell RW, Preshaw PM. Does the mode of administration of the Oral Health Impact Profile-49 affect the outcome score? J Dent. 2014;42(1):84-9.

12. Lutomski JE, van Exel NJ, Kempen Gl, et al. Validation of the CareRelated Quality of Life Instrument in different study settings: findings from The Older Persons and Informal Caregivers Survey Minimum DataSet (TOPICS-MDS). Qual Life Res. 2015;24(5):1281-93.

13. Wu AW, Jacobson DL, Berzon RA, et al. The effect of mode of administration on medical outcomes study health ratings and EuroQol scores in AIDS. Qual Life Res. 1997;6:3-10.

14. Puhan MA, Behnke M, Frey M, et al. Self-administration and intervieweradministration of the German Chronic Respiratory Questionnaire: instrument development and assessment of validity and reliability in two randomised studies. Health Qual Life Outcomes. 2004;2:1.

15. Puhan MA, Ahuja A, Van Natta ML, et al. Interviewer versus selfadministered health-related quality of life questionnaires - does it matter? Health Qual Life Outcomes. 2011;9:30.

16. Evans RA, Singh SJ, Williams JE, Morgan MD. The development of a self-reported version of the chronic heart questionnaire. J Cardiopulm Rehabil Prev. 2011;31(6):365-72.

17. Mulhern B, Longworth L, Brazier J, et al. Binary choice health state valuation and mode of administration: head-to-head comparison of online and CAPI. Value Health. 2013;16(1):104-13. 
18. Lozano Sánchez FS, March García JR, Carrasco Carrasco E, Lobos Bejarano JM. Perfil de los pacientes con claudicación intermitente en España. Estudio VITAL [Profile of patients with intermittent claudication in Spain. The VITAL Study]. Angiología. 2013;65(4):13140. Available from: http://saudepublica.bvs.br/pesquisa/resource/pt/ ibc-116639. Accessed in 2015 (Oct 16).

19. Lozano FS, González-Porras JR, March JR, et al. Diabetes mellitus and intermittent claudication: a cross-sectional study of 920 claudicants. Diabetol Metab Syndr. 2014;6(1):21.

20. Lozano FS, González-Porras JR, March JR, et al. Differences between women and men with intermittent claudication: a cross-sectional study. J Womens Health (Larchmt). 2014;23(10):834-41.

21. Lozano FS, March JR, González-Porras JR, et al. Relative value of the Ankle-Brachial Index of intermittent claudication. Int J Clin Pract. 2014;68(12):1478-82.

22. Badia X, Roset M, Montserrat S, Herdman M, Segura A. La versión española del EuroQol: descripción y aplicaciones [The Spanish version of EuroQol: a description and its applications. European Quality of Life scale]. Med Clin (Barc). 1999;112 Suppl 1:79-85.

23. Herdman M, Badia X, Berra S. El EuroQol-5D: una alternativa sencilla para la medición de la calidad de vida relacionada con la salud en atención primaria [EuroQol-5D: a simple alternative for measuring health-related quality of life in primary care]. Aten Primaria. 2001;28(6):425-30.

24. Swinscow TDV, Campbell MJ. Correlation and regression. $9^{\text {th }}$ ed. Southampton: BMJ Publishing Group; 1997.

25. Myers SA, Johanning JM, Stergiou N, et al. Claudication distances and the Walking Impairment Questionnaire best describe the ambulatory limitations in patients with symptomatic peripheral arterial disease. J Vasc Surg. 2008;47(3):550-555.

26. Nicolaï SP, Kruidenier LM, Rouwet EV, et al. The walking impairment questionnaire: an effective tool to assess the effect of treatment in patients with intermittent claudication. J Vasc Surg. 2009;50(1):89-94.

27. Frans FA, Zagers MB, Jens $S$, et al. The relationship of walking distances estimated by the patient, on the corridor and on a treadmill, and the Walking Impairment Questionnaire in intermittent claudication. J Vasc Surg. 2013;57(3):720-727.

28. Chetter IC, Dolan P, Spark JI, Scott DJ, Kester RC. Correlating clinical indicators of lower-limb ischaemia with quality of life. Cardiovasc Surg. 1997;5(4):361-6.

29. Bosch JL, Hunink MG. Comparison of the Health Utilities Index Mark 3 (HU13) and the EuroQol EQ-5D in patients treated for intermittent claudication. Qual Life Res. 2000;9(6):591-601.

30. Sani F, Todman JB. Experimental design and statistics for psychology: a first course. Oxford: Blackwell Publishing; 2006.

31. Feveile $H$, Olsen $O$, Hogh A. A randomized trial of mailed questionnaires versus telephone interviews: response patterns in a survey. BMC Med Res Methodol. 2007;7:27.

32. Bowling A. Mode of questionnaire administration can have serious effects on data quality. J Public Health (Oxf). 2005;27(3):281-91.
33. Mahe G, Ouedraogo N, Vasseur M, et al. Limitations of self-reported estimates of functional capacity using the Walking Impairment Questionnaire. Eur J Vasc Endovasc Surg. 2011;41(1):104-9.

34. Goldsmith KA, Dyer MT, Schofield PM, Buxton MJ, Sharples LD. Relationship between the EQ-5D index and measures of clinical outcomes in selected studies of cardiovascular interventions. Health Qual Life Outcomes. 2009;7:96.

35. de Vries M, Ouwendijk R, Kessels AG, et al. Comparison of generic and disease-specific questionnaires for the assessment of quality of life in patients with peripheral arterial disease. J Vasc Surg. 2005;41 (2):261-8.

Acknowledgements: We are grateful to the Saned Group (C/ Capitán Haya, 60, 10 Planta, 28020 Madrid, Spain) for assistance with technical and statistical aspects of the study

Participating scientific societies: Spanish Society of Angiology and Vascular Surgery (SEACV); Spanish Society of Doctors in Primary Medicine (SEMERGEN) and Spanish Society for Family and Community Medicine (SEMFyC)

Sources of funding: Project financed by Sociedad Española de Angiología y Cirugía Vascular (SEACV) and Ferrer Group (protocol no. SEA-NUL-2011-01)

Conflict of interests: We declare that we have no financial conflicts of interests in connection with this article

Date of first submission: May 29, 2015

Last received: September 28, 2015

Accepted: September 30, 2015

\section{Address for correspondence:}

Francisco Santiago Lozano Sánchez

Servicio de Angiología y Cirugía Vascular

Hospital Universitario de Salamanca

Paseo de San Vicente 58 - 182

37007 Salamanca

Spain

Tel. +34923291100

E-mail: lozano@usal.es 